Whyte, W., Green, G., and Whyte, W.M. (2012) Removal of microbe-carrying particles by high efficiency air filters in cleanrooms. International Journal of Ventilation, 10 (4). pp. 339-351.

Copyright (C) 2012 Veetech Ltd.

A copy can be downloaded for personal non-commercial research or study, without prior permission or charge

Content must not be changed in any way or reproduced in any format or medium without the formal permission of the copyright holder(s)

When referring to this work, full bibliographic details must be given

$\underline{\text { http://eprints.gla.ac.uk/64768 }}$

Deposited on: 12 May 2014

Enlighten - Research publications by members of the University of Glasgow http://eprints.gla.ac.uk 


\title{
Removal of microbe-carrying particles by high efficiency air filters in cleanrooms
}

\author{
W Whyte, G Green and WM Whyte \\ School of Engineering \\ University of Glasgow, G12 8QQ
}

\begin{abstract}
The removal efficiency of high efficiency air filters against microbe-carrying particles (MCPs) in the air supply of occupied rooms, such as cleanrooms, was determined. Knowing the size distribution of MCPs in the air to be filtered, and the removal efficiency of a filter against individual particle diameters, the overall removal efficiency was ascertained. A variety of filters were investigated, and it was found that a filter $90 \%$ efficient, when tested against sub-micrometre particles used in standard classification methods such as EN 1822, was greater than $99.99 \%$ efficient in removing MCPs. The effect of filter efficiency on the quality of the air supply, and the concentration of MCPs in cleanroom air was also studied. No practical improvement in airborne concentrations was obtained by filters that had a removal efficiency greater than $99.99 \%$ against MCPs. Use of a filter suitable for removing MCPs, rather than sub-micrometre particles, would give a reduction of about 6 to 8 -fold in the pressure drop over a filter, and a substantial reduction in the cost of running a cleanroom.
\end{abstract}

\section{Key words: Removal efficiency, microbes, micro-organisms, high efficiency air filters, HEPA, cleanrooms, energy efficiency, fan power}

\section{Introduction}

The airborne cleanliness of a cleanroom is directly related to the quality and quantity of the air supplied to it, and large quantities of filtered air are supplied to dilute and remove the contamination generated by the personnel and machines. The air supply to a cleanroom is filtered by either High Efficiency Particulate Air (HEPA) filters, which remove between $99.95 \%$ to $99.995 \%$ of the size of particle that most easily penetrates the filter $(0.2 \mu \mathrm{m}$ to $0.3 \mu \mathrm{m})$, or Ultra Low Penetration Air (ULPA) filters, which have a removal efficiency greater than $99.995 \%$ against the most penetrating particle size. The classification of such filters is given in Europe by EN 1822 (2009), and in the USA by IEST-RP-CC001.5 (2009) and IEST-RP-CC007.2 (2007).

Cleanrooms are very expensive to run, as they require large amounts of filtered and conditioned air, and hence use large amounts of energy. One manufacturing company has reported (Matsuki and Tanaka, 1998) that the energy consumption of their semiconductor plants exceeded 100 million kWh per year. It has been reported that $65 \%$ to $75 \%$ of the cost of running a cleanroom is energy costs (Schicht, 1999). Typical running costs for providing conditioned air are about $65 \%$ of the total energy costs, and air supply fans use about $30 \%$ of the total energy (Tschudi et al, 2001). The energy used by fans will vary according to the cleanliness of the room and the design of the air handling system, but much of the fan power is used to overcome the pressure drop across the high efficiency air supply filters, which is in the region of about $150 \mathrm{~Pa}$ when new, and about $400 \mathrm{~Pa}$ when soiled. This filter pressure can be as great as the entire pressure drop in simple air conditioning and distribution system used in an office, library, and similar area. If the performance of filters exceeds the actual requirements, large amounts of energy are wasted.

Cleanrooms are used by a wide variety of industries to minimise contamination from airborne particles. In the pharmaceutical, medical device, food, and similar manufacturing areas, the most important airborne contaminant is microbes. These types of cleanrooms are designed in a very similar way to those used in industries where inert sub-micrometre particles are important, and the same efficiency of air filters used, it being often incorrectly assumed that the size of MCPs is the same as the unicellular form (Kowalski et al, 1999). Most of the air supplied to a cleanroom is recirculated from the cleanroom, mixed with fresh air, conditioned, filtered, and then supplied to a cleanroom. Most of the air that is filtered is therefore very similar to that found in the cleanroom. 
Although microbes in their unicellular form are no more than a few micrometres in size, e.g. Staphylococcus aureus is about $0.9 \mu \mathrm{m}$ (Kowalski et al, 1999), they are seldom found in a unicellular form in the air of occupied rooms, but carried on skin cells (Davies and Noble, 1962). People shed approximately $10^{9}$ skin cells per day, the skin cells being about $33 \mu \mathrm{m} \times 44 \mu \mathrm{m}$ in surface area, and between $3 \mu \mathrm{m}$ and $5 \mu \mathrm{m}$ thick (McIntosh et al, 1978). A small but significant proportion of these skin cells carry skin microbes, and are found in the air with an average equivalent diameter of about 12 $\mu$ m (Noble et al, 1963; Whyte and Hejab, 2007). These particles are therefore known as microbe-carrying particles (MCPs). When people wear ordinary indoor clothing, the airborne dispersion rate is about 2400 MCPs per minute, although this will be reduced by about 10 to 100 times by cleanroom clothing, which acts as a body filter (Whyte and Bailey, 1985 and Whyte and Hejab, 2007).

Investigations into the removal efficiency of air filters against MCPs have been rarely reported. A study was made of air supply filters in a hospital ward (Whyte, 1968). The filters studied had a relatively low efficiency that ranged from about 90 to $99.9 \%$ against a test aerosol of about $5 \mu \mathrm{m}$ diameter. The removal efficiency of MCPs was found to be similar to the removal efficiency of the $5 \mu \mathrm{m}$ test aerosol. However, it has not been possible to test HEPA filters in situ because of the insensitivity of microbial air samplers, which cannot sample an airborne microbial concentration much below $1 / \mathrm{m}^{3}$. Air samplers are therefore incapable of measuring the penetration through HEPA filters, even if the filter challenge of MCPs is increased by the number of people, their activity, and the ineffectiveness of their clothing. However, with a knowledge of the size distribution of MCPs that has to be filtered, and the filter efficiency against individual particle diameters, the overall efficiency of a filter against the size distribution of MCPs can be calculated. A method has been devised and reported in this paper.

\section{Particle removal mechanisms}

HEPA and ULPA filters use fibrous media to remove particles. The media is usually made from glass fibres ranging in diameter from about $0.1 \mu \mathrm{m}$ to $10 \mu \mathrm{m}$, with spaces between fibres that are often very much larger than the particles captured. An ULPA filter has finer fibres than a HEPA filter. These fibres criss-cross randomly throughout the depth of the filter media and do not give a controlled pore size. As airborne particles pass through the filter paper, they are captured and retained by the fibres. The three main mechanisms involved in the removal of particles in high efficiency filter media are Brownian motion, interception, and impaction. In the process of capture by Brownian motion, very small particles move about randomly in the air because of the constant bombardment by other small particles and air molecules. The resultant random paths cause them to bump into the fibres of the filter, where they are deposited and retained. Interception occurs when airborne particles passing through the filter media come close enough to a fibre to be captured. Impaction occurs when particles with sufficient mass and momentum leave the airstream passing round a fibre and strike the fibre. The largest sizes of particles are removed by impaction, medium sizes by interception, and the smallest by Brownian motion. Gravitational settling may also cause deposition of large particles, but this mechanism is not important in high efficiency filters of the type we are interested, and not considered in this article.

\section{Calculation of filter removal efficiency}

Theoretical models have been developed to calculate the removal efficiency of particles of a known diameter by fibrous filters e.g. Davies (1973), Brown (1993), Dhaniyala and Liu (1999B), and Hinds (1999). The removal efficiency against a known particle diameter is firstly calculated for a single fibre that has a removal efficiency equivalent to the whole of the filter media. Knowing the single fibre efficiency, and the characteristics of the filter media, the filter efficiency of the whole filter against a single particle diameter can be calculated. The filter efficiency model used in this article is that described by Hinds (1999).

\subsection{Variables and constants}

Variables and constants used in the calculation of particle removal efficiency of fibrous filters against a known particle diameter are given below. 


\section{Fibre packing density $(\alpha)$}

The fibre packing density (also known as fibre volume fraction) is the proportion of the volume of the filter media that contains fibres. It may be calculated by dividing the fibre volume by the total volume of the filter media or, alternatively, calculated as follows:

$\alpha=\frac{m_{F}}{\rho_{F} t}$

Eqn 1

Where,

$m_{F}=$ mass of fibres per unit area of the filter media, $\rho_{F}=$ density of fibres, and $t=$ thickness of filter media.

\section{Kuwabara hydrodynamic factor $(\mathrm{Ku})$}

$K u$ is the Kuwabara hydrodynamic factor that compensates for the distortion of the airflow round a fibre owing to the proximity of other fibres. It is therefore related to the packing density of the filter media $(\alpha)$ and calculated as follows:

$K u=-\frac{\ln \alpha}{2}-\frac{3}{4}+\alpha-\frac{\alpha^{2}}{4}$

Eqn 2

For $d_{F}<2 \mu \mathrm{m}$, a slip corrected version of $K u$ should be used (Yeh and Liu, 1974), and adding $2 \lambda / d_{F}$ to the right hand side of the equation gives a satisfactory approximation (Kirsch and Stechkina, 1978).

\section{Equivalent fibre diameter $\left(d_{F}\right)$}

Filter media consists of a variety of fibre sizes that are distributed in the media in a random way. To model the single fibre removal of particles, it is necessary to obtain a single fibre diameter that has an equivalent removal efficiency to all of those in the filter media being studied. The pressure drop across the filter is measured at a given velocity, and the equivalent fibre diameter can be calculated using the following equation (Davies, 1973):

$d_{F}=\sqrt{\frac{\eta t U f(\alpha)}{\Delta p}}$

Eqn 3

Where,

$\eta=$ viscosity of air $=1.81 \times 10^{-5} \mathrm{~kg} / \mathrm{m} . \mathrm{s}, t=$ thickness of the filter, $U=$ velocity of air through media, $\mathrm{f}(\alpha)=64 \alpha^{1.5}\left(1+56 \alpha^{3}\right)$, and $\Delta p=$ pressure drop over the filter.

The factor $\mathrm{f}(\alpha)$, was derived by Davies from experimental measurements, and works well over a range of fibrous filter types. However, when the fibre diameter is about $1 \mu \mathrm{m}$, or less, the equation will overestimate the equivalent particle diameter. A method for correcting this is given by Dhaniyala and Liu (1999B), who suggest that the equivalent fibre diameter $\left(d_{F}\right)$ should be calculated as follows:

$d_{F}=\sqrt{\frac{4 m_{F}}{\pi \rho_{F} l_{F}}}$

Eqn 4

where, $l_{F}$ is the theoretical value of the specific fibre length within the filter media that can be determined as follows:

$l_{F}=\frac{\Delta P}{F(\alpha) \eta U}$

Eqn 5

where,

$$
F(\alpha)=\frac{4 \pi}{-\frac{1}{2} \ln (\alpha)+\frac{\alpha^{2}}{4}-\frac{3}{4}}
$$

Eqn 6

Using this method, Dhaniyala and Liu (1999B) calculated the equivalent fibre diameter of the filters they studied. These filters are also studied in this article and their calculated value of the equivalent fibre diameter used. 


\section{Slip correction factor $(C)$}

$C$ is a factor used to correct the effect of gas slip that occurs when small particles flow passed a particle or filter fibre. The following equation that was developed by Allen and Raabe (1985) was used.

$C=1+\frac{\lambda}{d_{P}}\left[2.34+1.05 \exp \left(-0.39 \frac{d_{P}}{\lambda}\right)\right]$

Eqn 7

Where,

$d_{P}=$ particle diameter, and $\lambda=$ gas mean free path of $0.066 \mu \mathrm{m}$ at $20^{\circ} \mathrm{C}$ and $101 \mathrm{kPa}$

\section{Stokes number (Stk)}

Stokes number is used to calculate the amount of impaction of particles on filter fibres, and is defined as following equation:

$S t k=\frac{\rho_{P} d_{P}{ }^{2} C U}{18 \eta d_{F}}$

Eqn 8

Where,

$\rho_{p}=$ density of particle, $d_{P}=$ diameter of particle, $C=$ slip factor, $U=$ velocity through filter media, $\eta=$ viscosity of air, and $d_{F}=$ equivalent diameter of fibres

\section{Diffusion coefficient $(D)$}

The diffusion coefficient is used to obtain the Peclet number, and calculated as follows:

$D=\frac{k T C}{3 \pi \eta d_{P}}$

Where,

$k=$ Boltzmann's constant $\left(1.38 \times 10^{-23}\right), T=$ temperature $\left(293^{\circ} \mathrm{K}\right), C=$ slip factor, $\eta=$ viscosity of air, and $d_{P}$ $=$ particle diameter

\section{Peclet number $(\mathrm{Pe})$}

This number is used to calculate the amount of particle deposition by Brownian diffusion, and is defined as follows:

$P e=\frac{U d_{F}}{D}$

Where $U=$ velocity through the filter, $d_{F}=$ equivalent fibre diameter, and $D=$ diffusion coefficient of particles of diameter $d_{F}$.

\subsection{Single fibre removal efficiency}

As discussed previously, the main mechanisms that remove particles within a fibrous filter are interception, inertial impaction, and Brownian diffusion. The calculation of the single fibre removal efficiency of particles of a known diameter by each of these mechanisms is described by Hinds (1999), and is as follows:

\section{Interception $\left(E_{R}\right)$}

The single fibre removal efficiency by interception against a given particle diameter is calculated by the equation suggested by Lee and Ramamurthi (1993):

$E_{R}=\frac{(1-\alpha) R^{2}}{K u(1+R)}$

Where, $R$ is an interception parameter that is calculated as follows:

$$
R=\frac{d_{P}}{d_{F}}
$$

where, $d_{P}=$ particle diameter, and $d_{F}=$ equivalent fibre diameter

$E_{R}$ should not exceed the maximum theoretical value of $1+R$. 


\section{Inertial impaction $\left(E_{I}\right)$}

When a particle has sufficient inertia, and cannot sufficiently change its direction, it may hit a fibre. This mechanism is dependant on Stokes number, and the single fibre efficiency can be calculated by the following equation suggested by Yeh and Liu (1974).

$E_{I}=\frac{S t k \cdot J}{2 K u^{2}}$

Eqn 12

where, the following equation can be used to calculate $J$, when $R<0.4$ :

$J=\left(29.6-28 \alpha^{0.62}\right) R^{2}-27.5 R^{2.8}$

When $R>0.4$, $J$ is given a value of 2 .

Brownian diffusion $\left(\boldsymbol{E}_{\boldsymbol{D}}\right)$ The single fibre removal efficiency, caused by Brownian diffusion, is calculated by the following equation that is based on experimental measurements (Kirsch and Fuchs, 1968):

$E_{D}=2 P e^{-2 / 3}$

Eqn 13

Increased interception by diffusing particles $\left(\boldsymbol{E}_{\boldsymbol{D} R}\right)$ The following term is suggested by Hinds (1999) to take account of the increased interception caused by the diffusing particles:

$E_{D R}=\frac{1.24 R^{2 / 3}}{(K u P e)^{1 / 2}}$

Eqn 14

Total single fibre efficiency $\left(\boldsymbol{E}_{\Sigma}\right)$ The total single fibre removal efficiency against particles of a known diameter can be obtained by combining the effect all of the individual mechanisms. This is discussed by Hinds (1999), and calculated as follows:

$E_{\Sigma}=1-\left(1-E_{R}\right)\left(1-E_{I}\right)\left(1-E_{D}\right)\left(1-E_{D R}\right)$

Eqn 15

\subsection{Overall efficiency of filter (E)}

After the total single fibre efficiency has been calculated, the efficiency of the complete filter is determined. This is calculated for a given diameter of particle by the use of the total single fibre efficiency $\left(E_{\Sigma}\right)$ in combination with the equivalent fibre diameter $\left(d_{F}\right)$, packing density $(\alpha)$, and filter thickness $(t)$, and use of the following equation. The derivation and use of this equation is explained by Hinds (1999).

Overall efficiency at a given particle diameter $=1-\exp \left(\frac{-4 \alpha E_{\Sigma} t}{\pi d_{F}}\right) \quad$ Eqn 16

\section{$4 \quad$ Properties of the air filters studied}

The properties of high efficiency filters are difficult to obtain, being proprietary information held by the manufacturers. However, Dhaniyala and Liu (1999A) reported the properties of various filter media they studied, and these are given in Table 1 . These filter media have particle removal efficiencies that range from $12 \%$ against $0.3 \mu \mathrm{m}$ particles to $99.99995 \%$ against $0.12 \mu \mathrm{m}$ particles, and include HEPA and ULPA filters commonly used in cleanrooms, as well as filters of a lower efficiency that might be suitable for the efficient removal of MCPs. The thickness of the fibre media was not reported by Dhaniyala and Liu (1999A) but was calculated from their data by use of the reformed Equation 1:

$t=\frac{m_{F}}{\rho_{F} \times \alpha}$

Eqn 17

where, $t=$ thickness of the filter media, $m_{F}=$ mass of fibres per unit area of media, $\alpha=$ fibre volume fraction and $\rho_{F}=$ density of filter filters, which is given by Dhaniyala and Liu (1999B) as $2.598 \mathrm{~g} / \mathrm{cm}^{3}$.

Table 1 Properties of filter media studied

\begin{tabular}{|l|l|l|l|l|l|l|l|}
\hline Manufacturer's & Particle & $m_{F}=$ mass & $\alpha=$ & $t=$ & $d_{F}=$ & $U=$ & Airflow \\
\hline
\end{tabular}




\begin{tabular}{|l|l|l|l|l|l|l|l|}
\hline $\begin{array}{l}\text { filter code } \\
\text { number }\end{array}$ & $\begin{array}{l}\text { removal } \\
\text { efficiency } \\
\text { (test aerosol } \\
\text { diameter })\end{array}$ & $\begin{array}{l}\text { of fibres } \\
\text { per unit } \\
\text { area } \\
\left(\mathbf{g} / \mathbf{c m}^{2}\right)\end{array}$ & $\begin{array}{l}\text { fibre } \\
\text { volume } \\
\text { fraction }\end{array}$ & $\begin{array}{l}\text { media } \\
\text { thickness } \\
\mathbf{( \mathbf { c m } )}\end{array}$ & $\begin{array}{l}\text { equivalent } \\
\text { fibre } \\
\text { diameter } \\
(\mu \mathbf{m})\end{array}$ & $\begin{array}{l}\text { velocity } \\
\text { through } \\
\text { media } \\
\mathbf{( c m} / \mathbf{s}) *\end{array}$ & $\begin{array}{l}\text { resistance } \\
\text { (Pa) at the } \\
\text { given } \\
\text { velocity }\end{array}$ \\
\hline HF 0493 & $\begin{array}{l}12 \%(0.3 \\
\mu \mathrm{m})\end{array}$ & 0.0106 & 0.0703 & 0.0580 & 8.01 & 5.3 & 34 \\
\hline HF 0533 & $\begin{array}{l}55 \%(0.3 \\
\mu \mathrm{m})\end{array}$ & 0.00797 & 0.0756 & 0.0406 & 3.68 & 5.3 & 34 \\
\hline HD 2063 & $\begin{array}{l}97 \%(0.3 \\
\mu \mathrm{m})\end{array}$ & 0.00781 & 0.0764 & 0.0393 & 1.66 & 5.3 & 145 \\
\hline HB 5433 & $\begin{array}{l}99.985 \% \\
(0.3 \mu \mathrm{m})\end{array}$ & 0.00732 & 0.0741 & 0.0380 & 1.05 & 5.3 & 311 \\
\hline HA 8183 & $\begin{array}{l}99.9995 \% \\
(0.12 \mu \mathrm{m})\end{array}$ & 0.00781 & 0.0658 & 0.0457 & 0.89 & 2.54 & 423 \\
\hline HA 8193 & $\begin{array}{l}99.99995 \% \\
(0.12 \mu \mathrm{m})\end{array}$ & 0.00781 & 0.0790 & 0.0380 & 0.80 & 2.54 & 564 \\
\hline
\end{tabular}

* air velocity is through the medium, and not the filter face velocity

\section{Correlation of theoretical and experimental efficiencies}

Given in Table 2 is a comparison of the removal efficiencies of the filter media against known particle diameters, as calculated both theoretically and measured experimentally. The calculated efficiency was obtained by use of the theoretical model described by Hinds (1999), and outlined in the previous sections of this paper when using the properties of the filter medium given in Table 1 . The experimental removal efficiencies against given diameters of particles were those measured and reported by Dhaniyala and Liu (1999A).

Table 2 Comparison of particle removal efficiency obtained by calculation and measurement

\begin{tabular}{|l|l|l|l|l|l|l|}
\hline $\begin{array}{l}\text { Manufacturer's } \\
\text { filter code } \\
\text { number }\end{array}$ & $\begin{array}{l}\text { Diameter of } \\
\text { particle } \\
\text { challenge }(\boldsymbol{\mu m})\end{array}$ & $\begin{array}{l}\text { Velocity though } \\
\text { filter medium } \\
\mathbf{( m / s )}\end{array}$ & \multicolumn{2}{|l|}{$\begin{array}{l}\text { Removal efficiency by } \\
\text { measurement }\end{array}$} & \multicolumn{2}{l}{$\begin{array}{l}\text { Removal efficiency } \\
\text { by calculation }\end{array}$} \\
\hline HF 0493 & 0.3 & 0.053 & $23 \%$ & $8.9 \%$ & $21 \%$ & $12 \%$ \\
\hline HF 0533 & 0.3 & 0.053 & $63 \%$ & $55 \%$ & $49 \%$ & $35 \%$ \\
\hline HD 2063 & 0.3 & 0.053 & $96 \%$ & $96 \%$ & $93 \%$ & $90 \%$ \\
\hline HB 5433 & 0.3 & 0.053 & $99.95 \%$ & 99.98 & $99.60 \%$ & $99.68 \%$ \\
\hline HA 8183 & 0.12 & 0.0254 & $99.9995 \%$ & NR & $99.9987 \%$ & NR \\
\hline HA 8193 & 0.12 & 0.0254 & $99.99998 \%$ & NR & $99.9999 \%$ & NR \\
\hline
\end{tabular}

NR= Experimental results not reported by Dhaniyala and Liu (1999A).

Table 2 shows that the efficiencies calculated by Hinds' theoretical model are close to those measured. Having demonstrated that the removal efficiency of filters against given diameters of particles can be calculated theoretically, the removal efficiency against the known size distribution of MCPs is now calculated.

\section{$6 \quad$ Filter removal efficiencies of MCPs}

\subsection{Size distribution of microbe-carrying particles}

MCPs have a variety of shapes and densities that influence their movement in air. It is therefore conventional and convenient to consider airborne particles in terms of equivalent particle diameter, which is the diameter of a sphere of unit density that has the same aerodynamic properties as the particle being considered. 
It was established several decades ago that most of the microbes in air of occupied rooms are carried on skin cells, which are dispersed by the people (Davies and Noble, 1962). The size distribution of MCPs has been reported in hospital rooms (Noble et al, 1963), hospital air conditioning plants (Whyte, 1968), and from people wearing cleanroom clothing (Whyte, 1986; Whyte and Hejab, 2007). These results are very similar and compiling these results, the size distribution of MCPs in the air of occupied rooms can be obtained, and is given in Table 3.

Table 3 Occurrence of MCPs equal to, and greater than, given equivalent diameters

\begin{tabular}{cccccc}
\hline Equivalent particle diameter $(\mu \mathrm{m})$ & $\leq 1$ & $\leq 5$ & $\leq 12$ & $\leq 20$ & $\leq 50$ \\
\hline Cumulative occurrence & $1 \%$ & $25 \%$ & $50 \%$ & $75 \%$ & $95 \%$ \\
\hline
\end{tabular}

It may be seen from Table 3 that the size distribution of MCPs has an average equivalent particle diameter of $12 \mu \mathrm{m}$, and the occurrence of MCPs larger than $20 \mu \mathrm{m}$ is $25 \%$, and smaller than $4 \mu \mathrm{m}$ is $75 \%$. The frequency of occurrence of MCPs with an equivalent particle diameter above $50 \mu \mathrm{m}$ is relatively small, being less than $5 \%$ and presumably caused by the lower likelihood of such large particle diameters being dispersed from people, and the greater effect of gravitational settling onto surfaces. Microbes found on the human skin, and in the air of cleanrooms, are almost entirely vegetative bacteria, with an occasional sporebearing bacterium, yeast, and mould (Noble and Somerville, 1974 and Whyte et al, 1982). They will therefore have a unicellular size that is unlikely to be much less than $1 \mu \mathrm{m}$ (Kowalski et al, 1999), and at that diameter they have a frequency of occurrence of about $1 \%$. The size distribution given in Table 3 conforms well to a log-normal one, with a median diameter of $12 \mu \mathrm{m}$ and a geometric standard deviation of 2.7.

\subsection{Calculation of removal efficiency of MCPs by high efficiency filters}

As discussed in the previous paragraph, the size distribution of MCPs in the air of occupied rooms conforms to a log-normal distribution. The probability density function (pdf) of such a distribution is given by the following equation:

$$
f(x)=\frac{1}{x \sigma \sqrt{2 \pi}} \cdot e^{-\frac{(\ln x-\mu)^{2}}{2 \sigma^{2}}}
$$

Where, $x=$ variable, $\mu=2.48$, and $\sigma=0.99$

Using Equation 18, the frequency of occurrence of the distribution of particle diameter of MCPs was calculated, and is shown in Figure 1 between the limits of $0.5 \mu \mathrm{m}$ and $50 \mu \mathrm{m}$. It is the larger of the two curves and known as the 'unmodified probability density function (pdf)' curve. 


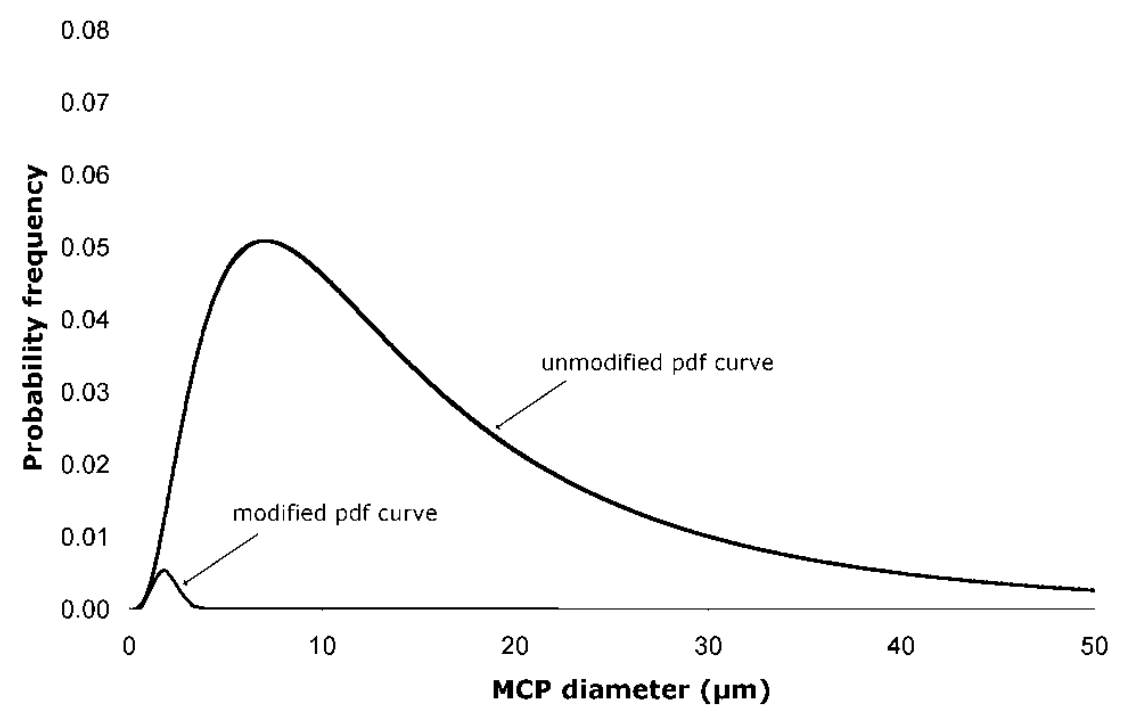

Figure 1 Unmodified and modified pdf curves

If the frequency of occurrence of the diameters found in the size distribution of MCPs is multiplied by the filter removal efficiency at these diameters, the result can be plotted as a 'modified pdf curve', and is shown as the smaller curve in Figure 1. The area under the unmodified curve represents all of the MCPs found in unfiltered air, and the area under the modified pdf curve represents the proportion of MCPs that penetrates through the filter. Therefore, if the area under the modified curve is calculated as the proportion of the area under the unmodified pdf curve, the penetration of the size distribution of MCPs is obtained. The percentage removal efficiency of the filter can then be calculated.

Given in Table 4 is the particle removal efficiency of the range of filter medium whose properties are given in Table 1. The particle removal efficiency of the filters against the most penetrating particle size (MPPS) is calculated by the theoretical method, and given in column two; the particle removal efficiency is therefore determined in the same way as required in EN 1822. Given in column three is the overall removal efficiency against the established size distribution of MCPs, as determined by the method described in the previous paragraph.

Table 4 Removal efficiency of MCPs and particles at the filter's MPPS

\begin{tabular}{|l|l|l|}
\hline $\begin{array}{l}\text { Manufacturer's } \\
\text { filter code number }\end{array}$ & $\begin{array}{l}\text { Particle removal efficiency } \\
\text { at the MPPS }\end{array}$ & $\begin{array}{l}\text { Removal efficiency of } \\
\text { MCPs }\end{array}$ \\
\hline HF 0493 & $11 \%$ at $0.42 \mu \mathrm{m}$ & $96.70 \%$ \\
\hline HF 0533 & $35 \%$ at $0.3 \mu \mathrm{m}$ & $99.64 \%$ \\
\hline HD 2063 & $87 \%$ at $0.22 \mu \mathrm{m}$ & $99.9946 \%$ \\
\hline HB 5433 & $99.15 \%$ at $0.2 \mu \mathrm{m}$ & $99.999903 \%$ \\
\hline HA 8183 & $99.987 \%$ at $0.22 \mu \mathrm{m}$ & $99.9999982 \%$ \\
\hline HA 8193 & $99.9988 \%$ at $0.22 \mu \mathrm{m}$ & $99.99999989 \%$ \\
\hline
\end{tabular}

It may be seen in Table 4 that the removal efficiency of MCPs is very much higher than the removal efficiency of particles at their MPPS. It can also be seen that as the particle removal efficiency of the filter increases, the removal efficiency against MCPs becomes proportionally greater. The reason for this can be explained by reference to Figures 2 and 3. Figure 2 gives the particle removal of the highest efficiency medium (HA 8193) and shows that particle penetration only occurs within a narrow size range of between about $0.1 \mu \mathrm{m}$ to $0.45 \mu \mathrm{m}$. Figure 3 shows the removal efficiency of the least efficient filter medium (HF 0493) and shows that it allows a much wider range of particles of between about $0.1 \mu \mathrm{m}$ and $4 \mu \mathrm{m}$ to penetrate. Therefore, proportionally, a lower penetration (higher efficiency) over the size distribution of MCPs will occur with higher efficiency filters. 


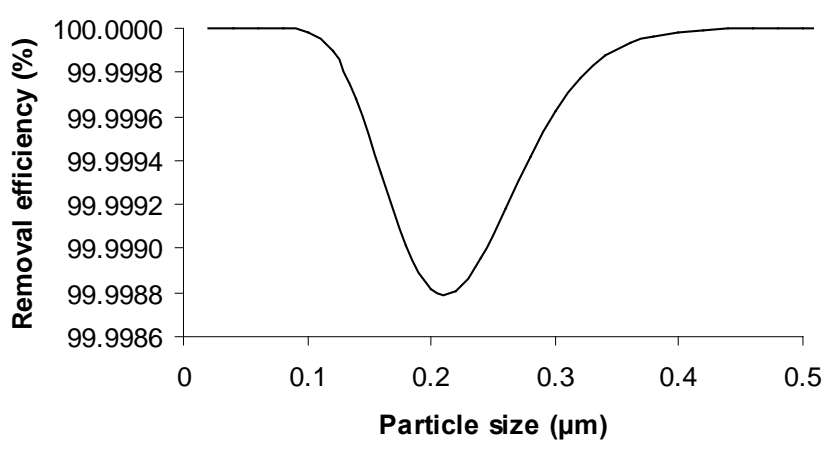

Figure 2 Particle removal efficiency of HA 8193 filter medium

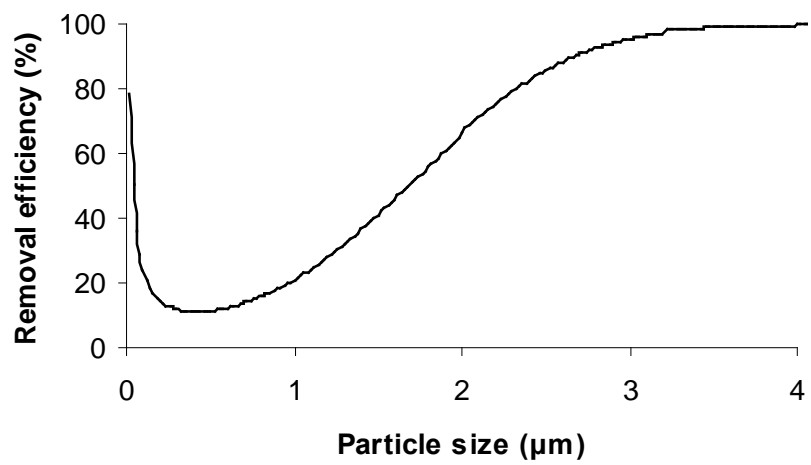

Figure 3 Particle removal efficiency of HF 0493 filter medium

\subsection{Effect of filter efficiency on airborne microbial concentrations in cleanrooms}

\subsubsection{Methods of calculating the effect of filter efficiency on airborne microbial concentration}

Shown in Figure 4 is a diagram of a typical ventilation system used in non-unidirectional airflow cleanrooms. Because of the large quantities of filtered air that are required for cleanrooms, and the high cost of air conditioning and filtering the outside fresh air, about $90 \%$ of the air is recirculated from the cleanroom. The recirculated air is mixed with filtered outside air, the temperature and humidity adjusted in the air conditioning plant, and it is filtered by high efficiency filters in the ceiling of the cleanroom. A similar method of air distribution is used in unidirectional cleanrooms.

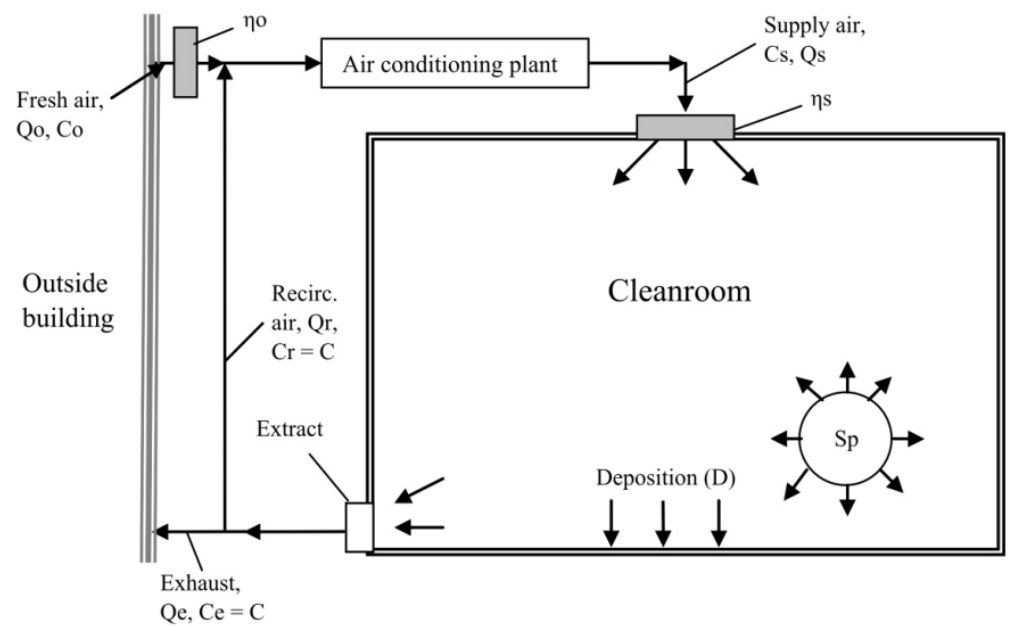

Figure 4 Air supply and extract system in a non-unidirectional cleanroom $\square=$ air filter. The meaning of the abbreviations is given in the text. 
19:

The number of MCPs that enter a cleanroom through terminal air filters can be calculated by Equation MCPs supplied through air filters (no./s) $=\left(C_{O} \cdot Q_{O}\left[1-\eta_{O}\right]+C_{R} \cdot Q_{R}\right)\left(1-\eta_{S}\right)$

Where, $C_{O}$ and $C_{R}$ are the microbial concentrations in the outside and recirculated air $\left(\right.$ no. $\left./ \mathrm{m}^{3}\right)$, respectively; $Q_{O}$ and $Q_{R}$ are the air supply rates of the outside and recirculated air $\left(\mathrm{m}^{3} / \mathrm{s}\right)$, respectively;

$\eta_{O}$ and $\eta_{S}$ are the microbial removal efficiencies of the outside and main supply air filters, respectively.

The concentration of MCPs in the recirculated air $\left(C_{R}\right)$ can be assumed to have the same concentration as the cleanroom.

The filtered supply air enters the cleanroom, and mixes with MCPs dispersed by personnel which are dispersed at the rate of $S_{P}$ per second. Cleanroom air is then extracted through grilles that are usually sited at a low level round the walls; this is the main method of removing MCPs from a cleanroom. However, deposition onto cleanroom surfaces will also remove MCPs. The deposition velocity $\left(V_{D}\right)$ of MCPs with an average equivalent diameter of $12 \mu \mathrm{m}$ is $0.0046 \mathrm{~m} / \mathrm{s}$ (Whyte, 1986). Although some deposition occurs on small surfaces, such as machinery and tables, only the floor area $\left(A_{D}\right)$ is considered in this article. In the steady-state condition there is a mass-balance between the generation of particles and their removal in a cleanroom. By use of a mass balance equation, a solution for the airborne concentration in the room can be obtained and this is given in Equation 20. The full derivation of this equation, and its application, will be the basis of a further publication.

Airborne concentration in non-unidirectional cleanroom $\left(\right.$ no. $\left./ \mathrm{m}^{3}\right)=\frac{C_{O} \cdot Q_{O}\left(1-\eta_{O}\right)\left(1-\eta_{S}\right)+S_{P}}{Q_{O}+Q_{R} \eta_{S}+V_{D} \cdot A_{D}}$ Eqn 20

\subsubsection{Effect of filter efficiency on the airborne microbial concentration in non-unidirectional cleanrooms}

Equation 20 allows the airborne concentration of MCPs in a cleanroom to be calculated, when filters of different efficiencies are installed. A typical non-unidirectional airflow cleanroom with a floor area of $10 \mathrm{~m} \mathrm{x}$ $10 \mathrm{~m}$ and a height of 3 metres was considered. The room had an air supply rate of $3 \mathrm{~m}^{3} / \mathrm{s}$, and hence an air change rate of 36/hour. The air supply to the cleanroom was made up of $90 \%$ recirculated air from the cleanroom, and $10 \%$ from the fresh air. The microbial concentration of the outside air was taken as $100 / \mathrm{m}^{3}$ and the MCPs assumed to have a similar size distribution to that found in the cleanroom (Whyte, 1968). The removal efficiency of the fresh air filters is assumed to be the same as the supply air filters. Four people work in the cleanroom and, when wearing cleanroom clothing, their MCPs dispersion rate is assumed to be 3/s per person (Whyte and Hejab, 2007), or 12/s for all four people.

Table 5 The effect of filter efficiency on the airborne microbial concentration in a cleanroom

\begin{tabular}{ll}
\hline $\begin{array}{l}\text { Filter removal efficiency } \\
\text { of MCPs (\%) }\end{array}$ & $\begin{array}{l}\text { Airborne microbial concentration } \\
\text { per } \mathrm{m}^{3} \text { in cleanroom }\end{array}$ \\
\hline 10 & 35.2427 \\
20 & 24.0000 \\
50 & 9.2417 \\
90 & 3.8558 \\
95 & 3.6316 \\
99 & 3.4964 \\
99.9 & 3.4709 \\
99.99 & 3.4685 \\
99.999 & 3.4682 \\
99.9999 & 3.4682 \\
\hline
\end{tabular}

Given in Table 5 are the concentrations of MCPs found in the cleanroom for filter efficiencies that range from $10 \%$ to $99.9999 \%$. It can be seen that when the filter efficiency increases from $10 \%$ to $99.99 \%$, the airborne microbial concentration drops to a level that changes very little with an increase in filter removal 
efficiency. Any change in the removal of MCPs by filters more efficient that about $90 \%$ could not be measured by even the most accurate air sampler. The reason for the diminishing returns is that the microbial dispersion from personnel remains constant, irrespective of filter efficiency, and there is no practical reduction in the microbial concentration in the supply air after the filter removal efficiency reaches about 99.99\%.

\subsubsection{Comparison of the MCPs coming from the supply air compared to those dispersed by personnel}

Using the values of the variables given in the previous two sections of this article, Equation 19 was used to calculate the number of MCPs supplied to the room per second by the air supply. This was calculated for filters with different removal efficiencies and given in the first two columns of Table 6 . The number of MCPs dispersed by personnel was assumed to be 12 per second, and this value is inserted in column three. The ratio of MCPs originating from the supply air compared to those dispersed by personnel is given in column four.

It may be seen in Table 6 that as the filter removal efficiency increases, there is a drop in the proportion of MCPs in the cleanroom that come from the filtered air compared to that dispersed by personnel. At very low filter efficiencies, more MCPs come from the supply air than personnel, but when the filter efficiency reaches $99 \%$, 99.9\% and 99.99\%, the proportion of MCPs from the supply air is equivalent to about 1 in about 120, 1280 and 12,800, respectively, of the MCPs in the cleanroom air.

Table 6 The effect of filter efficiency on the proportion of microbes in a cleanroom that come from supply air

\begin{tabular}{|l|l|l|l|}
\hline $\begin{array}{l}\text { Filter removal } \\
\text { efficiency against } \\
\text { MCPs (\%) }\end{array}$ & $\begin{array}{l}\text { MCPs supplied in } \\
\text { filtered air supply } \\
\text { (no./s) }\end{array}$ & $\begin{array}{l}\text { MCPs dispersed by } \\
\text { personnel (no/s) }\end{array}$ & $\begin{array}{l}\text { Ratio of MCPs from } \\
\text { supply air to those } \\
\text { dispersed by personnel }\end{array}$ \\
\hline 10 & 109.93 & 12 & $9.2: 1$ \\
\hline 20 & 71.040 & 12 & $5.9: 1$ \\
\hline 50 & 19.976 & 12 & $1.7: 1$ \\
\hline 90 & 1.3411 & 12 & $1: 8.9$ \\
\hline 95 & 0.5653 & 12 & $1: 21$ \\
\hline 99 & 0.0974 & 12 & $1: 123$ \\
\hline 99.9 & 0.0094 & 12 & $1: 1276$ \\
\hline 99.99 & 0.000937 & 12 & $1: 12810$ \\
\hline 99.999 & 0.000094 & 12 & $1: 128100$ \\
\hline 99.9999 & 0.000009 & 12 & $1: 1281000$ \\
\hline
\end{tabular}

\subsection{Pressure drop across filters}

Table 1 gives information on the characteristics of the filter medium studied, and includes the pressure drop. However, the pressure drop across the two most efficient filters was measured at a velocity that was half of the rest of the filters i.e. $2.54 \mathrm{~cm} / \mathrm{s}$ instead of $5.3 \mathrm{~cm} / \mathrm{s}$. The airflow through these types of filters is laminar and the relation between the pressure drop across the filters and the air volume passing through is linear; this was confirmed in Dhaniyala and Liu (1999A). The removal efficiency of the filters was recalculated to obtain the efficiency against the MPPS, and these are given in Table 7 along with the expected pressure drop at a velocity of $5.3 \mathrm{~cm} / \mathrm{s}$.

Table 7 Pressure drop across filter media

\begin{tabular}{|l|l|}
\hline $\begin{array}{l}\text { Particle removal efficiency } \\
\text { at the MPPS }\end{array}$ & $\begin{array}{l}\text { Expected airflow pressure } \\
\text { drop (Pa) at } 5.3 \mathbf{~ c m} / \mathbf{s}\end{array}$ \\
\hline $11 \%$ & 34 \\
\hline $35 \%$ & 34 \\
\hline $87 \%$ & 145 \\
\hline
\end{tabular}




\begin{tabular}{|l|l|}
\hline $99.15 \%$ & 311 \\
\hline $99.987 \%$ & 883 \\
\hline $99.9988 \%$ & 1177 \\
\hline
\end{tabular}

It can be seen in Table 7 that the pressure drop across a filter that has a removal efficiency of $87 \%$ against the MPPS is 6 to 8 times less than the pressure drop across filters which would be commonly used in cleanrooms i.e. those with a removal efficiency of $99.987 \%$ or $99.9988 \%$.

\section{$7 \quad$ Discussion and conclusions}

The main object of this investigation was to ascertain the removal efficiency of air supply filters against microbe-carrying particles (MCPs) in cleanrooms. At present, little or no heed is taken during the design of cleanrooms as to whether the airborne contamination to be filtered is sub-micrometre particles or MCPs, and the same efficiency of filters is generally installed in both situations. In cleanrooms, most of the air to be filtered is recirculated from the cleanroom, and MCPs found in cleanroom air are dispersed from personnel on skin particles and have an average equivalent diameter of about $12 \mu \mathrm{m}$; MCPs in the outside air have a similar size distribution (Whyte, 1968). Air filters will, therefore, be much more efficient in removing MCPs than sub-micrometre particles. However, it has not been possible to ascertain the efficiency of high efficiency filters in situ, as microbial air samplers are not sensitive enough to measure the extremely low microbial concentrations that penetrate these filters.

MCPs that are filtered by the cleanroom supply filters are mainly recirculated from the cleanroom, and their size distribution conforms to a log-normal distribution, with a median equivalent particle diameter of 12 $\mu \mathrm{m}$, and a geometric standard deviation of $2.7 \mu \mathrm{m}$. Using this size distribution, and a filter's calculated efficiency against known particle diameters, the overall removal efficiency was obtained. The method derived can also be used to obtain the removal efficiency of filters against the much smaller size distribution of inert particles in a cleanroom, and hence be used to report the overall removal efficiencies of filters against the cumulative particle counts of the type measured in cleanrooms by particle counters, rather than against discrete particle diameters. The removal efficiency of filters was calculated using the method described by Hinds (1999), and the accuracy of the method demonstrated by comparing it to experimental measurements reported by Dhaniyala and Liu (1999A). The overall removal efficiency of a range of filters against the size distribution of MCPs was thus obtained, and when the particle removal efficiency of a filter was $87 \%$ according to criterion set by EN 1822, the overall removal efficiency against MCPs was greater than $99.99 \%$.

The likely airborne microbial concentration in a typical non-unidirectional cleanroom was studied with respect to air supply filters of different efficiencies. The air passing through low efficiency filters contributed to the airborne concentration in the cleanroom but as the filter efficiency increased the airborne contribution of the MCPs in the supply air was reduced to a minimum that was not reduced by a further increase in removal efficiency. This occured at a removal efficiency of $99.99 \%$.

A calculation was also carried out to compare the contribution of MCPs from the filtered air supply, to the only other source of microbial contamination in a cleanroom i.e. personnel. It was found that the air passing through a filter that removes 99\% of the MCPs, would contribute about 1 in 120 to the MCPs in the air of a typical cleanroom. However, as the filter efficiency increases to $99.9 \%$ and then to $99.99 \%$, the contribution decreases from about 1 in 1280 to 1 in 12,800. It therefore appears that there is little advantage in providing a filter that is more efficient than $99.99 \%$, as the further decrease in contamination by using more efficient filters will be insignificant. Should it be necessary to reduce the airborne microbial concentration in a cleanroom, there are much more effective measures that can be used e.g. the use of more efficient cleanroom clothing, minimising the number of personnel in the cleanroom, reducing the activity of personnel, or increasing the dilution of the airborne contamination by increasing the air supply volume.

Summarising the conclusions with respect to filter efficiency, it would appear that a filter $90 \%$ efficient, as measured by standard test methods such as EN 1822, would give a removal of at least $99.99 \%$ of MCPs and is more than adequate to ensure that the contribution of microbial contamination from the supply air is insignificant. 
It was also ascertained that a filter suitable for MCPs removal i.e. one that is $90 \%$ efficient against EN 1822 (or other similar standard filter test methods), has a pressure drop of about 6-8 times less than a filter of the type typically used in cleanroom to remove sub-micrometre particles. Using a filter with this reduced pressure drop will result in a substantial drop in energy consumption, and hence the cost of running a cleanroom.

\section{References}

1. Allen MD and Raabe OG: (1985) "'Slip correction measurements of spherical solid aerosol particles in an improved Millikan apparatus”, Aerosol Science and Technology, 4, pp269-286.

2. Brown RC: (1993). “Air filtration”, Elsevier Science.

3. Davies RR and Noble WC: (1962). “'Dispersal of bacteria in desquamated skin”, Lancet, ii, pp12951297.

4. Davies CN: (1973). “Air filtration”, Academic Press.

5. Dhaniyala S and Liu BYH: (1999A). "Investigations of particle penetration in fibrous filters Part 1. Experimental”'. Journal of the IEST, January/February, pp32-40.

6. Dhaniyala S and Liu BYH: (1999B). "Investigations of particle penetration in fibrous filters Part II. Theoretical”, Journal of the IEST, March/April, pp40-46.

7. EN 1822, Parts 1 to 5: (2009). "High efficiency air filters (EPA, HEPA and ULPA)”. European Committee for Standardization.

8. Hinds W C: (1999). “Aerosol technology - properties, behaviour, and measurement of airborne particles”, second edition. Wiley - Interscience, New York, USA.

9. IEST-RP-CC001.5: (2009). "HEPA and ULPA filters". Recommended Practice of the Institute of Environmental Sciences and Technology, Arlington Heights, USA.

10. IEST-RP-CC007.2: (2007). "Testing ULPA filters". Recommended Practice of the Institute of Environmental Sciences and Technology, Arlington Heights, USA.

11. Kirsch AA and Fuchs NA (1968): “Studies of fibrous filters-III: Diffusional deposition of aerosols in fibrous filters”, Annals of Occupational Hygiene, 11, pp299-304.

12. Kirsch AA and Stechkina, IB: (1978). “The theory of aerosol filtration with fibrous filters” In: Shaw, DT (Ed), Fundamentals of Aerosol Science, Wiley, New York.

13. Kowalski WJ, Bahnfleth WP and Whittam TS: (1999). "Filtration of airborne microorganism: modelling and prediction”. ASHRAE Transactions: Research, 105(2), pp4-17.

14. Lee KW and Ramamurthi M: (1993) '“Filter collection’’ In; Willeke, K and Baron, PA (Eds), Aerosol Measurement: Principles, Techniques, and Applications, Van Nostrand Reinhold, New York.

15. Matsuki M and Tanaka N: (1998). "Energy saving system for air conditioning of clean room for semiconductor factory (estimate of FMU system)”. Oki Technical Review, 63, pp49-52.

16. McIntosh C, Lidwell OM, Towers AG and Marples RR: (1978). "The dimensions of skin fragments dispersed into the air during activity”, Journal of Hygiene, Cambridge, 81: pp471-479.

17. Noble WC, Lidwell OM and Kingston D: (1963). "The size distribution of airborne particles carrying micro-organisms”'. Journal of Hygiene, Cambridge, 61: pp385-391.

18. Noble WC and Somerville DA: (1974). "Microbiology of human skin”, WB Saunders and Co., London.

19. Schicht HH: (1999). "Cost efficiency and energy saving concepts for cleanrooms". In "Cleanroom Design - Second Edition”, pp141-155.

20. Tschudi B, Sartor D and Xu T: (2001). “An energy efficiency guide for use in cleanroom programming”. Report LBNL-49223, Lawrence Berkeley National Laboratory, Berkeley, USA.

21. Whyte W: (1968). "Bacteriological aspects of air conditioning plant", Journal of Hygiene, Cambridge. 66, pp567-584.

22. Whyte W, Bailey PV, Tinkler J, McCubbin I, Young L, and Jess J: (1982). “An evaluation of the routes of bacterial contamination occurring during aseptic pharmaceutical manufacturing”, Journal of Parenteral Science and Technology, 36(3), pp102-107.

23. Whyte W and Bailey PV: (1985). "Reduction of microbial dispersion by clothing', Journal of Parenteral Science and Technology, 39(1), pp51-61.

24. Whyte W: (1986). “'Sterility assurance and models for assessing airborne contamination'”. Journal of Parenteral Science and Technology, 40(5), pp188-197. 
25. Whyte W and Hejab, M: (2007). "Particle and microbial airborne dispersion from people”, European Journal of Parenteral \& Pharmaceutical Sciences, 12(2), pp39-46.

26. Yeh HC and Liu BYH: (1974). “Aerosol filtration by fibrous filters”, Journal of Aerosol Science. 5, pp191-217. 